\title{
Endoscopic treatment of complicated bile duct stricture after surgery for traumatic bile duct injury
}

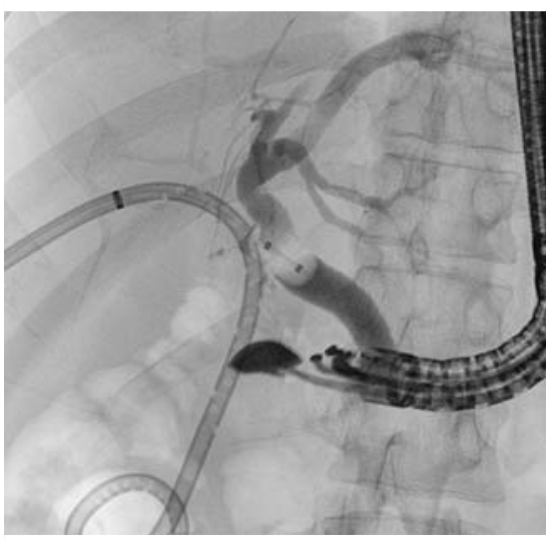

- Fig. 1 Occlusive percutaneous cholangiography using a $12-\mathrm{mm}$ Fogarty balloon to dilate the common bile duct and make it visible under endoscopic ultrasound.

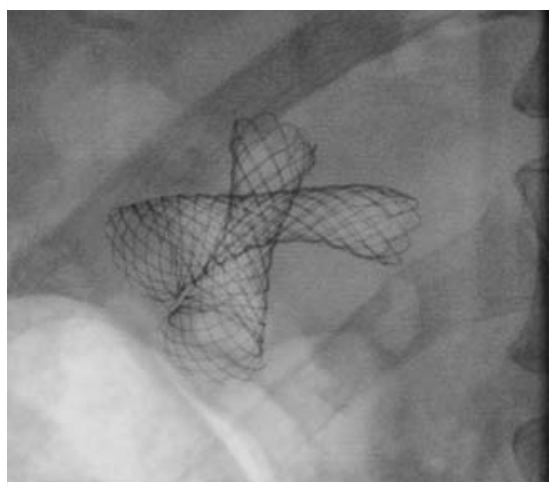

> Fig. 4 "Hand-tailored," fully covered, self-expandable metal stents placed through the choledochoduodenostomy crosswise to avoid excessive tension of the anastomotic area.

Hepatic lesions are common in abdominal traumas [1] and generally involve liver parenchyma.

Nevertheless, bile duct lesions are rare and challenging to treat $[2,3]$.

Biliodigestive anastomoses are the most frequently performed surgeries [3], but the risk of long-term adverse events is high, especially for biliary anastomotic strictures [4].

Here we present a case of traumatic biliary disconnection previously treated by

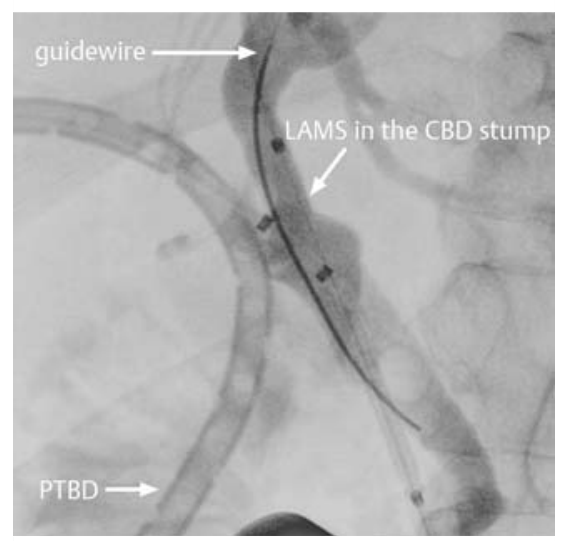

- Fig. 2 To safely open the lumen-apposing metal stent in a small-caliber common bile duct, the stent was placed as deep as possible in the biliary tract through a guidewire.

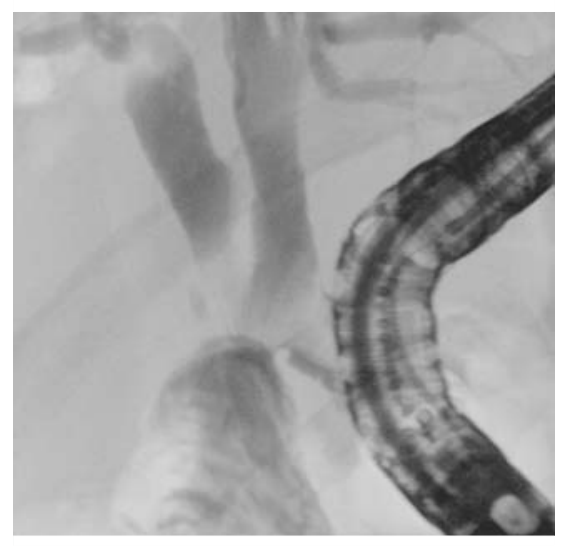

- Fig. 5 Final oucome on the hepaticojejunostomy.

biliodigestive latero-lateral anastomosis on Roux-en-Y-loop, complicated by anastomotic stricture.

A 42-year-old man without relevant comorbidities was unseated from his horse and reported a severe bile leak due to intrapancreatic biliary tract disconnection. For this reason, he underwent hepaticojejunal latero-lateral anastomosis on Roux-en-Y-loop, with previous ligation of the distal choledocus.

After six months, a biliary anastomotic stricture developed and percutaneous

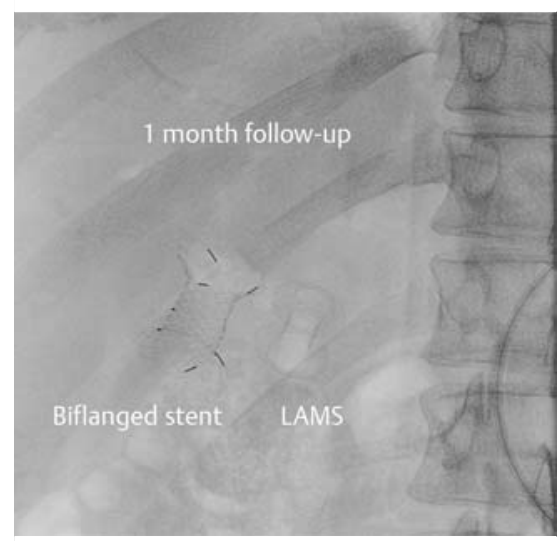

- Fig. 3 Biflanged stent and lumen-apposing metal stent at 1-month follow-up.

transhepatic biliary drainage was performed as the primary treatment.

Because of the very low quality of life due to poor tolerance/compliance with percutaneous transhepatic biliary drainage, the patient was referred to our endoscopy center.

At first, a standard approach to the major duodenal papilla was attempted with a duodenoscope (ED-127; Pentax Medical), but it failed because the intrapancreatic biliary tract was completely disconnected.

At this point, an occlusive cholangiography was performed (using a Fogarty balloon pushed into the bile duct through the percutaneous access) ( $\triangleright \mathbf{F i g} \mathbf{1}$ ) in order to make the common bile duct visible on endoscopic ultrasound. The Hot AXIOS electrocautery-enhanced delivery system (Boston Scientific) was chosen to change the approach, and a fully covered, $8 \times 8-\mathrm{mm}$ lumen-apposing metal stent (LAMS) was released between the duodenum and the choledocal stump ( $\triangleright$ Fig. 2). Then a fully covered, $16-\mathrm{mm} \times 2-\mathrm{cm}$ biflanged metal stent (Nagi Stent; EuroMedical Corp.) was placed through the hepaticojejunostomy using the percutaneous access to achieve stable dilation of the anastomotic stricture ( $\mathbf{F i g . 3}$ ). 


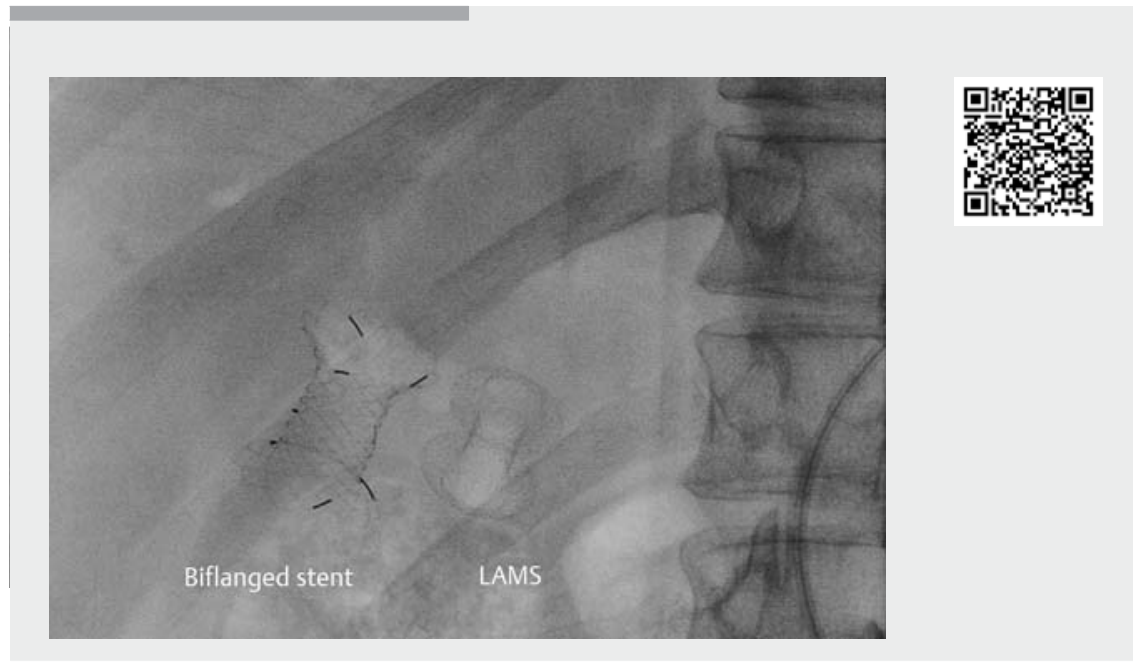

$\checkmark$ Video 1 A case of traumatic choledochal disconnection previously treated by biliodigestive latero-lateral anastomosis on Roux-en-Y-loop complicated by anastomotic stricture and solved by "tailored" endoscopic treatment.

[1] Navsaria PH, Nicol AJ, Edu S et al. Selective nonoperative management in 1106 patients with abdominal gunshot wounds: conclusions on safety, efficacy, and the role of selective $C T$ imaging in a prospective single center study. Ann Surg 2015; 261: 760-764

[2] Tiwari C, Shah H, Waghmare M et al. Management of traumatic liver and bile duct laceration. Euroasian J Hepato Gastroenterol 2017; 7: 188-190

[3] Wong VW, Gee A, Hansen P et al. Isolated avulsion of the common hepatic duct from blunt abdominal trauma. Case Rep Surg 2012; 2012: 254563

[4] Dimou FM, Adhikari D, Mehta HB et al. Incidence of hepaticojejunostomy stricture after hepaticojejunostomy. Surgery 2016; 160: 691-698

Bibliography

At the six-month follow-up, both stents were removed, and two "hand-tailored," fully covered, 6-mm $\times 3-\mathrm{cm}$ self-expandable metal stents (WallFlex; Boston Scientific) were placed through the new choledocoduodenostomy to consolidate the anastomosis ( $\triangleright$ Video 1 ). The stents were positioned crosswise in order to avoid excessive tightening on the walls of the biliary ducts ( $\triangleright$ Fig. 4 ).

These stents were removed after six months and, at the cholangiography, the choledocoduodenostomy was patent ( $\vee$ Fig.5). The patient remained asymptomatic and no recurrence of symptoms was reported.

Endoscopy_UCTN_Code_TTT_1AR_2AG

\section{Competing interests}

None

\section{The authors}

Valerio Pontecorvi ${ }^{1}$, Lorenzo Dioscoridi ${ }^{1}$, Edoardo Forti ${ }^{1}$, Marcello Cintolo ${ }^{1}$, Aurora Giannetti ${ }^{1}$, Simone Vagnarelli ${ }^{2}$, Massimiliano Mutignani ${ }^{1}$

1 Digestive and Interventional Endoscopy Unit, Azienda Socio-Sanitaria Territoriale Grande Ospedale Metropolitano Niguarda, Milano, Italy

2 Interventional Radiology, San Giovanni Hospital, Rome, Italy

\section{Corresponding author}

\section{Massimiliano Mutignani, MD \\ Endoscopy Unit Niguarda Ca-Granda Hospital, Piazza dell'Ospedale Maggiore 3, 20162 Milano, Italy Fax: +39-02-64442911 massimiliano.mutignani@ospedaleniguarda. it}

DOI https://doi.org/10.1055/a-1045-4246

Published online: 2.12.2019

Endoscopy 2020; 52: E172-E173

(c) Georg Thieme Verlag KG

Stuttgart · New York

ISSN 0013-726X

\section{ENDOSCOPY E-VIDEOS}

https://eref.thieme.de/e-videos

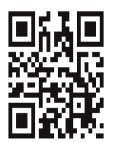

Endoscopy E-Videos is a free access online section, reporting on interesting cases and new techniques in gastroenterological endoscopy. All papers include a high quality video and all contributions are freely accessible online.

This section has its own submission website at https://mc.manuscriptcentral.com/e-videos 